\title{
Expression of Molecular Markers in Tumours of Patients with Breast Cancer
}

\author{
D O Shapochka ${ }^{1 *}$, S P Zaletok ${ }^{1}$ and M I Gnidyuk ${ }^{2}$
}

${ }^{1}$ R.E. Kavetsky Institute of Experimental Pathology, Oncology and Radiobiology of NAS of Ukraine, Kyiv, Ukraine

${ }^{2}$ Ivano-Frankivsk Regional Oncology Dispensary, Ukraine

\begin{abstract}
The expression of transcription factor NF-KB (p50 and p65), ER, PR, Her2/neu, Ki-67, p53, Bcl-2 and E-cadherin in tumor tissue of 132 patients with breast cancer was investigated by immunohistochemistry. As a result of researches the correlation between Grade and expression of ER, PR, Bcl-2, Ki-67 and p65-subunit of NF-KB was defined. The level of proliferation was correlated with ER, PR, Bcl-2, p53 and Her2/neu expression. Also the correlation between some of investigated markers was found. Thus, high level of NF-KB nuclear expression was associated with Her2/neu hyperexpression and negative status of ER, PR and Bcl-2. These data may indicate poor prognosis and resistance to chemotherapy in breast cancer patients with activated NF-KB, but it requires further research and retrospective analysis of large number of patients.
\end{abstract}

Keywords: Breast cancer; Receptors of steroid hormones; Her2/neu; NF-Kb; Ki-67; p53; Bcl-2; E-cadherin

\section{Introduction}

Breast Cancer (BC) is by far the most frequent cancer in women, and the main cause of death in women of 35-55 years old. Despite the improvement of diagnostic methods and chemotherapeutic regimes overall 5-year survival of patients is significantly depends on the stage of disease and in the period 2000-2005 is 56.2\% in Ukraine [1].

Such clinical characteristics as age, menstrual status, tumor size, lymph node status and morphological characteristics of the tumor (histological type, Grade, lymphatic/vascular invasion) traditionally are an important prognostic factors. However, in the last decades understanding of tumor nature has been greatly enlarged by molecular biology researches, which allowed the application of tumor's molecular features for prognosis of the disease flow.

Most molecular markers that are studied today, involved in pathological processes which together determine the ability of cells to malignant growth [2]. Thus, for the entry of normal cells into mitosis is required exogenous growth signal. However, malignant transformation of cells may be accompanied by loss depending on these signals. In breast tumors often occurs overexpression of Her2/neu, which is one of a family of receptors Epidermal Growth Factor Receptor (EGFR). This family consists of four members: EGFR/ErB1/HER1, c-erbB2/ Her2/Neu, ErB3/HER3 and ErB4/HER4. There are 3 main biological effects mediated by EGFR: inhibition of apoptosis, stimulation of proliferation and modification of adhesion molecules. Her2/neu overexpression can be detected by immunohistochemical method, or by enzyme-linked immunoassay in circulation. In breast cancer tumors it often associates with amplification of the gene and can be detected by Real-time PCR and fluorescence (FISH), or Chromogenic in situ Hybridization (CISH). Positive Her2/neu is associated with clinical and morphological parameters of the tumor, indicating the poor prognosis of the disease.

Another important process towards malignant transformation of cells is the blockage of apoptosis. The most common molecular event that leads to this outcome is the inactivation of the protein p53. According to different authors, up to $50 \%$ of breast tumors have mutations of the p53 gene. P53 is a key component of the defense system, which blocks the formation of atypical cells. Protein p53 is activated in response to
DNA damage, oncogene activation, hypoxia, oxidative stress, viral infection and other anomalous processes leading to cell cycle arrest and damage repair or apoptosis. Mutations in the p53 gene ensuring the increase of genetic instability, high levels of proliferation and apoptosis blockade. There are two basic methods for determining the status of p53 in tumors: genetic (eg sikvens or PCR) and IHC analysis (which was used in this study). According to the literature, positive nuclear reaction with p53 in $90-100 \%$ of cases corresponds missens mutations of p53 gene that determine mutant immunophenotype [3]. But the negative reaction with antibodies against p53 only in $80 \%$ of cases indicates the absence of mutations in the gene, while in $20 \%$ of cases protein is just do not expressed [3].

In breast tumours, as in tumours at other sites, the presence of mutant p53 is associated with a decrease in sensitivity to therapy and occurrence of aggressive disease.

An important regulator of apoptosis is the family of proteins Bcl. Some members of this family are inhibitors of apoptosis (Bcl-2, Bcl-Xl), the rest - inductors ( $\mathrm{Bax}, \mathrm{Bad})$. The most important predictive value for $\mathrm{BC}$ among this family has Bcl-2. This protein inhibits release of mitochondrial cytochrome $\mathrm{c}$ and apoptosis-inducing factor [4] as well as lipid peroxidase reaction in the mitochondrial membrane [5], which leads to inhibition of apoptosis. The level of Bcl-2 in cells is regulated by $\mathrm{p} 53$ protein on the principle of feedback, thus the co-expression of these factors is very rare [6]. Many authors confirmed the correlation between overexpression of $\mathrm{Bcl}-2$ and positive status of steroid hormone receptors; negative - of p53 and Her2/neu; low level of proliferation $[7,8]$. In addition, overexpression of $\mathrm{Bcl}-2$ is associated with increased overall and disease-free survival of patients with breast cancer [7-9].

*Corresponding author: D.O. Shapochka, R.E. Kavetsky Institute of Experimental Pathology, Oncology and Radiobiology of NAS of Ukraine, Kyiv, Ukraine, E-mail: shapochka.dm@gmail.com

Received July 18, 2013; Accepted August 10, 2013; Published August 12, 2013

Citation: Shapochka DO, Zaletok SP, Gnidyuk MI (2013) Expression of Molecular Markers in Tumours of Patients with Breast Cancer. J Cytol Histol 4: 184. doi: 10.4172/2157-7099.1000184

Copyright: (C) 2013 Shapochka DO, et al. This is an open-access article distributed under the terms of the Creative Commons Attribution License, which permits unrestricted use, distribution, and reproduction in any medium, provided the original author and source are credited. 
Many authors confirmed the correlation between overexpression of Bcl-2 with positive status of steroid hormone receptors, negative p53 and Her2/neu; low proliferation [7,8]. In addition, overexpression of Bcl-2 is associated with increased overall and disease-free survival of patients with breast cancer [7-9].

The most studied and important in malignant transformation are cadherins. The central molecule, which causes adhesion between epithelial cells, is E-cadherin. Reduced expression of E-cadherin, which often occurs in breast tumors on the one hand leads to reduced intercellular adhesion and promotes invasive growth, and the other leads to the release of $\beta$-catenin, its translocation to the nucleus and stimulation of cell proliferation by transcriptional activity $[10,11]$. In practice - downregulation of E-cadherin in ductal adenocarcinoma of breast cancer correlates with low grade, positive lymph node and Her2/ neu status, poor prognosis [12].

A summary measure of apoptosis blockade and independence of tumour from growth signals is the proliferation level of tumour cells. To date, the most common method for determining proliferative activity in the tumour is the immune histochemical study of Ki67 expression.

Estrogen and progesterone receptors were the first predictive molecular markers for BC. They are proteins that specifically bind these steroid hormones and then induce the transcription of genes involved in the processes of differentiation, proliferation, adaptation and protein biosynthesis. Great prognostic value associated primarily with high sensitivity of ER-and PR-positive tumors to hormone therapy. Many studies demonstrated that an increase in expression level of ER and PR increases the effect of hormonal therapy. For example ER+/ PR- tumours are hormone-sensitive in 55-60\% of cases, and ER + / PR +- in $80 \%$.

Next marker that was included in clinical practice is HER2/ neu, which positive status in patients with BC correlated with high sensitivity to trastuzumab targeted therapy.

Promising targets for therapy may be transcription factors because they affect on transcription of oncogenes that could play an important role in the formation of chemo-and radioresistance. One of the transcription factors, dysfunction of which often occurs in malignant tumors, is a nuclear transcription factor NF- $\kappa B$. NF- $\kappa B$ family is composed of polypeptides c-rel, p50, p52, p65 (RelA), p68 (RelB), p100 and p105, that belong to the rel-family proteins homologous to oncogene v-rel. The best studied of them are proteins $\mathrm{p} 50$ and p65, which form the classic NF- $\mathrm{kB}$ heterodimer (p50/p65). In most cells, $\mathrm{NF}-\kappa \mathrm{B}$ is present as a latent, inactive, $\mathrm{I}-\kappa \mathrm{B}$-bound complex in the cytoplasm. Under external stimuli, I- $\kappa B$ proteins are degraded via the ubiquitin-proteasome pathway, leading to release of the active form of $\mathrm{NF}-\kappa \mathrm{B}$ that translocates to the nucleus, where it regulates the expression of target genes. NF- $\mathrm{kB}$ was discovered as a protein that specifically binds to a sequence of positive regulator of immunoglobulin's $\kappa$ light chain gene. Further studies established the crucial role NF- $\kappa B$ in the formation of immune response. Later the involving of NF- $\mathrm{KB}$ proteins in processes of tumor development and growth was found. In many tumors (including breast cancer, colon cancer, prostate cancer, lymphoid cancers, and probably many others) NF- $\mathrm{KB}$ is constitutively active and located in the nucleus [13]. Recent studies indicate the important role of NF- $\mathrm{kB}$ in maintaining the viability of tumor cells. Another important point is the influence of NF- $\mathrm{kB}$ on tumor sensitivity to chemotherapy and immune reactions [14]. Montagut et al. [15] showed that activation of NF- $\kappa \mathrm{B}$ was significantly correlated with resistance to chemotherapy in breast cancer patients. Furthermore, in some cases NF- $\kappa \mathrm{B}$ activation increased after chemotherapy exposure, which may cause the formation of chemoresistance [15-17]. Besides the direct relationship between activation of NF- $\kappa B$ and chemoresistance, it is studied the correlation of NF- $\mathrm{kB}$ expression with other markers. There are many contradictions in the results of such studies associated with absence of a standard method of determining the NF- $\mathrm{kB}$ activation, and the differences in interpretation of results obtained by the same method. However, most results suggest that NF- $\kappa B$ is activated mainly in ER-negative andHer2/neu-positive tumors [15,18-22]. These tumors usually have a high proliferative index and Grade and form a group with the worst prognosis and high chemoresistance. These data also suggest indirectly that the activity of NF- $\mathrm{KB}$ affects the sensitivity of tumors to therapy. This indicates that the possibility of regulation the $\mathrm{NF}-\kappa \mathrm{B}$ activity open a new features in therapy of tumors [23].

\section{Materials and Methods}

132 patients with breast cancer were included in the study. All tumors belong to invasive ductal carcinoma with different tumor grade. Clinical data of patients and tumor characteristics shown in Table 1.

Expression of molecular markers (Table 2) was determined by immunohistochemistry on formalin-fixed paraffin-embedded $4 \mu \mathrm{m}$ tissue sections. Antigen retrieval performed at temperature $98^{\circ} \mathrm{C}$ for $30 \mathrm{~min}$, endogenous peroxidase was blocked with $0.03 \%$ hydrogen peroxide for $5 \mathrm{~min}$. Slides were then washed with Tris-buffered saline solution at $\mathrm{pH} 7.6$ and incubated with the primary antibodies for 30 min: Estrogen Receptor a (Monoclonal Rabbit Anti-Human, RTU, clone SP1, Dako), Progesterone Receptor (Monoclonal Mouse AntiHuman, RTU, clone PgR 636, Dako), c-erbB2 (Polyclonal Rabbit Anti-Human, 1:1000, Dako), NF- $\kappa B$ p50 (NLS) (Polyclonal Rabbit Anti-Human, 1:200, sc114, Santa Cruz Biotechnology), p-NF- $\kappa B$ p65 (Ser 536) (Polyclonal Rabbit Anti-Human, sc-33020, Santa Cruz Biotechnology), Ki-67 (Monoclonal Mouse Anti-Human, RTU, clone MIB-1, Dako), p53 (Polyclonal Rabbit Anti-Human, 1:100, RP 106, Diagnostic BioSystems), Bcl-2 (Monoclonal Mouse AntiHuman, RTU, clone 124, Dako), E-cadherin (Monoclonal Mouse Anti-Human, RTU, clone NCH-38, Dako). After rinsing sections incubated with HRP from FLEX detection system (Dako) for $20 \mathrm{~min}$. Sections were then treated with DAB for $3 \mathrm{~min}$ and counterstained with haematoxylin. Slides were washed in tap water, dehydrated, and mounted with glass coverslips.

For interpretation of reaction with antibodies against ER, PR, p50

\begin{tabular}{|c|c|c|}
\hline Characteristic & n & 100 \\
\hline N of patients & 132 & \multicolumn{2}{|c|}{60 years } \\
\hline age & \multicolumn{2}{|c|}{$28-81$} \\
\hline mean & Stage \\
\hline range & 17 & 13 \\
\hline I & 87 & 66 \\
\hline III & 28 & 21 \\
\hline & Axillary nodal status & 62 \\
\hline- & 82 & 38 \\
\hline 1 & 50 & 13 \\
\hline 2 & Tumor Grade & 64 \\
\hline 3 & 17 & 23 \\
\hline
\end{tabular}

Table 1: Clinical data of patients and morphological characteristics of tumors. 


\begin{tabular}{|c|c|c|}
\hline Status of marker & $\mathbf{n}$ & $\%$ \\
\hline \multicolumn{3}{|l|}{ ER } \\
\hline- & 36 & 27 \\
\hline+ & 96 & 73 \\
\hline \multicolumn{3}{|l|}{ PR } \\
\hline- & 54 & 41 \\
\hline+ & 78 & 59 \\
\hline \multicolumn{3}{|l|}{ Her2/neu } \\
\hline- & 92 & 70 \\
\hline+ & 40 & 30 \\
\hline \multicolumn{3}{|l|}{ p65 } \\
\hline Low $(\mathrm{H}<100)$ & 109 & 83 \\
\hline High $(H>100)$ & 23 & 17 \\
\hline \multicolumn{3}{|l|}{ p50 } \\
\hline Low $(\mathrm{H}<100)$ & 49 & 37 \\
\hline High $(H>100)$ & 83 & 63 \\
\hline \multicolumn{3}{|l|}{ Ki-67 } \\
\hline Low $(\mathrm{H}<100)$ & 41 & 31 \\
\hline High $(H>100)$ & 91 & 69 \\
\hline \multicolumn{3}{|l|}{ p53 } \\
\hline- & 80 & 61 \\
\hline+ & 52 & 39 \\
\hline \multicolumn{3}{|l|}{$\mathrm{Bcl}-2$} \\
\hline Low & 83 & 63 \\
\hline High & 49 & 37 \\
\hline \multicolumn{3}{|l|}{ E-cadherin } \\
\hline Low & 54 & 41 \\
\hline High & 78 & 59 \\
\hline
\end{tabular}

Table 2: Expression of molecular markers in tumors of patients with breast cancer.

and $\mathrm{p} 65$ the $\mathrm{H}$-score method was evaluated. The score is obtained by the formula:

$\mathrm{H}=3 \mathrm{x} \%$ of strongly staining nuclei $+2 \mathrm{x} \%$ of moderately staining nuclei $+\%$ of weakly staining nuclei.

Expression level of marker with $\mathrm{H}>100$ was classified as high, $\mathrm{H}=50-99$ - moderate and $\mathrm{H}<50-$ low.

Her2/neu expression level was determined by reaction with antibodies against HER2/neu. For interpretation of reaction such criteria were applied: 0 (negative): No staining is observed or membranous staining is observed in less than $10 \%$ of the tumor cells. 1+ (negative): A faint/barely perceptible staining is detected in more than $10 \%$ of the tumor cells. The cells are stained in part of their membrane. $2+$ (equivocal): A weak to moderate complete membrane staining is observed in more than $10 \%$ of the tumor cells. $3+$ (positive): A strong complete membrane staining is observed in more than $30 \%$ of the tumor cells. Tumors with expression level 0 and $1+$ considered HER2/neu-negative, and with $2+$ and $3+-$ positive.

Proliferation level was determined by reaction with antibodies against Ki-67: 0 - No nuclear staining is observed in tumor cells; 1 nuclear staining is detected in $1-10 \%$ of the tumor cells; $2-11-20 \%$; $3-21-50 \%$; $4->50 \%$. In tumors with level of Ki-67 expression " 0 " and "1" - proliferation level was considered as low; and with " 2 ", " 3 " and “4” - high.

P53-status of tumors was determined by the level of accumulation in the nuclei of tumor cells. Negative (0) - nuclear staining is detected in less than $10 \%$ of the tumor cells; Positive: $1-11-20 ; 2-21-50 \%$; 3 $-51-75 \% ; 4->75 \%$.
Bcl-2 and E-cadherin expression level was determined by reaction with antibodies against corresponding antibodies. The level of expression was considered low (1) in the presence of weak cytoplasmic (for Bcl-2) and membranous (for E-cadherin) staining in more than $10 \%$ tumor cells, moderate (2) - moderate staining in more than $10 \%$ tumor cells , high (3) - intense staining over $10 \%$ of tumor cells.

For statistical analysis of the data the program SPSS was used. To identify the correlation the Pearson coefficient of correlation was defined, and to verify its validity $\chi^{2}$ test was used.

\section{Results}

In the tumors of patients with BC expression levels of these molecular markers were investigated: estrogen and progesterone receptors (ER and PR), Her2/neu, Ki-67, p53, NF- $\mathrm{kB}$ subunits (p50 and p65 proteins), Bcl-2 and E-cadherin. 96 tumors (73\%) were ERpositive $(\mathrm{H}>10)$ and $36(27 \%)$ - ER-negative $(\mathrm{H} \leq 10)$. PR-status was positive $(\mathrm{H}>10)$ in 78 cases $(59 \%)$, and negative - in $54(41 \%)$. The Her2/neu overexpression was identified in 40 tumors (30\%), other 92 (70\%) patients had negative Her $/$ neu status. The study of NF- $\mathrm{kB}$ (p50 and p65) expression have shown high levels of p50 $(\mathrm{H}>100)$ and p65 $(\mathrm{H}>100)$ in tumors, respectively, in $83(63 \%)$ and $23(17 \%)$ patients. It should be noted that all tumors with high expression of p 65 had high levels of p50.

Proliferative activity of tumors was high (Ki-67> 20\%) in 91 (69\%) and low $(\mathrm{Ki}-67<20 \%)$ in $41(31 \%)$ patients. p53 status in tumors was positive in $52(39 \%)$ and negative in $80(61 \%)$ patients. Bcl2 expression was high in $49(37 \%)$ and low in $83(63 \%)$ tumours. And E-cadherin expression was high in 78 (59\%) and low in 54 (41\%) cases.

The next relationships between clinical and morphological characteristics of tumors and molecular markers expression were found

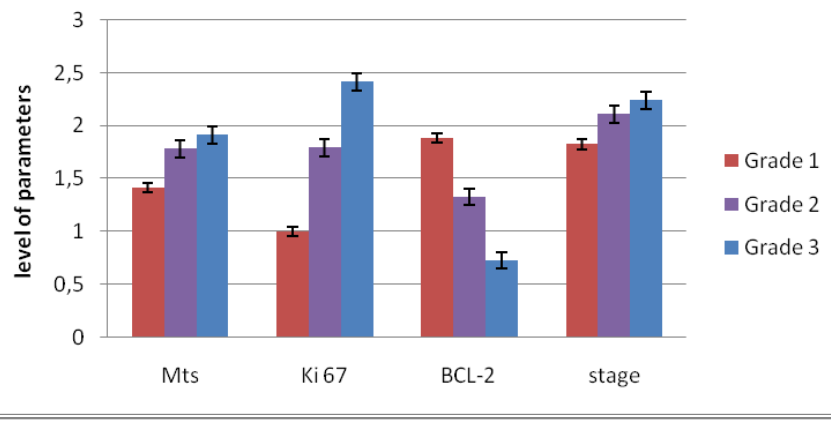

b)

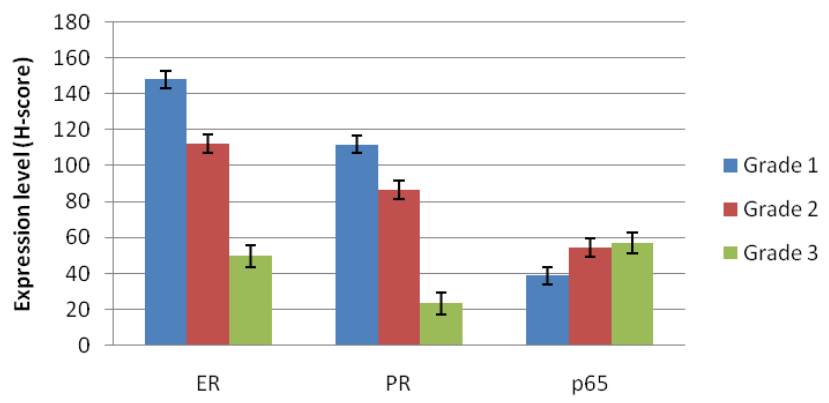

Figure 1: Correlation between Grade and: a) lymph nodes status, stage, Ki-67 and $\mathrm{Bcl}-2$ expression; b) ER, PR and p65 expression. 
Citation: Shapochka DO, Zaletok SP, Gnidyuk MI (2013) Expression of Molecular Markers in Tumours of Patients with Breast Cancer. J Cytol Histol 4: 184. doi: 10.4172/2157-7099.1000184

Page 4 of 6

in our study: the direct correlation between Grade and lymph node status $(\mathrm{p}=0,013)$, stage $(\mathrm{p}=0,019)$, proliferation index $(\mathrm{Ki}-67, \mathrm{p}<0,01)$; also observed an inverse correlation between Grade and expression level of ER $(\mathrm{p}<0,01), P R(\mathrm{p}<0,01)$ and Bcl-2 $(\mathrm{p}<0,01)$ (Figure 1).

a)

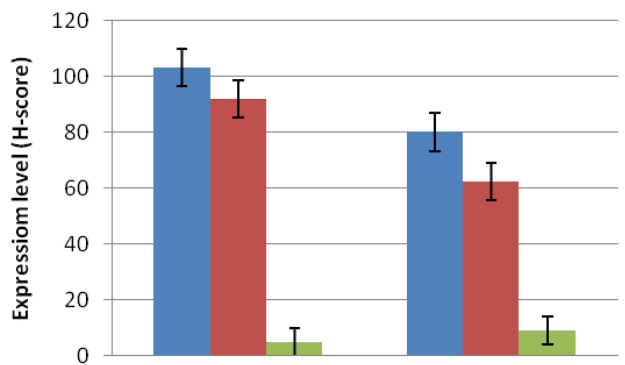

- Her $2 /$ neu $0,1+$

- Her2/neu $2+$

- Her2/neu $3+$

ER

PR

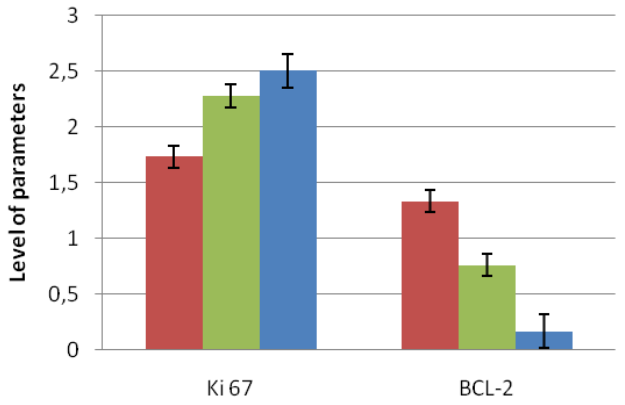

Figure 2: Correlation between Her2/neu status and: a) ER and PR expression b) $\mathrm{Ki}-67$ and $\mathrm{Bcl}-2$ expression.
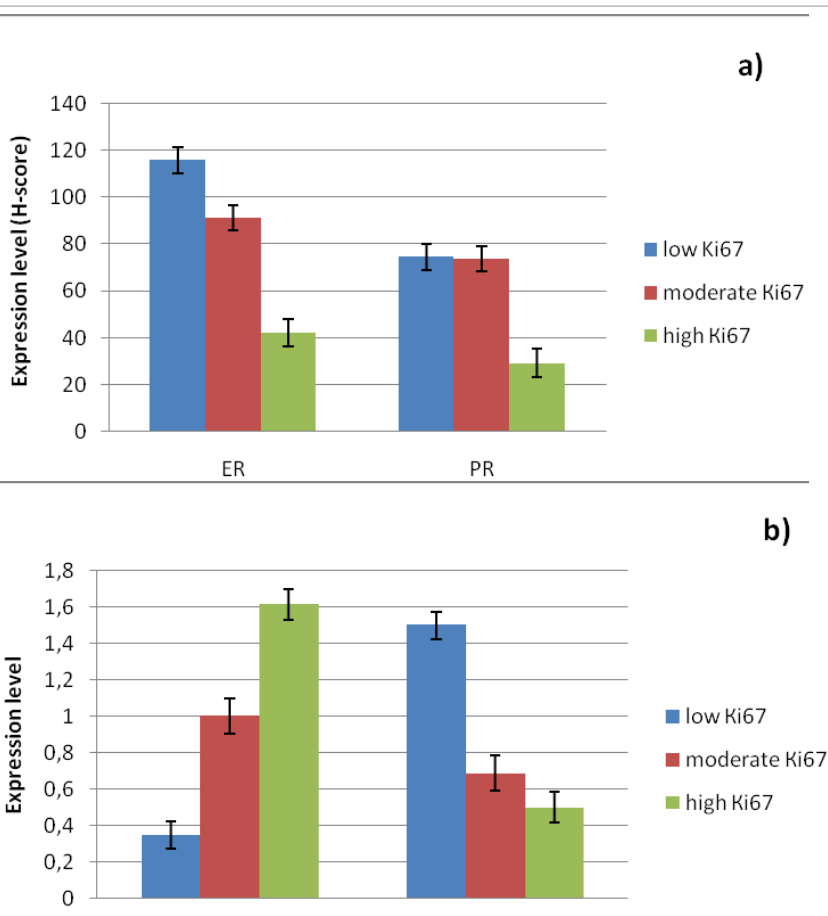

Figure 3: Correlation between proliferation level and: a) ER and PR expression; b) p53 and Bcl-2 expression.

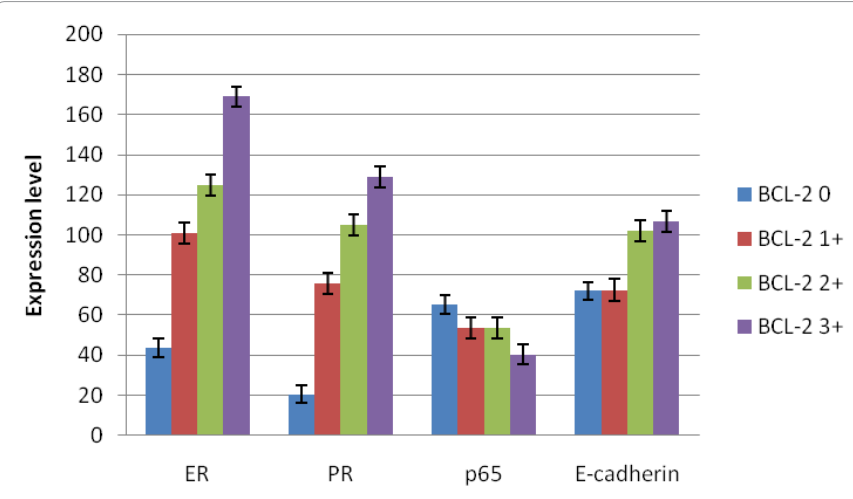

Figure 4: Correlation between $\mathrm{Bcl}-2$ expression and other markers.

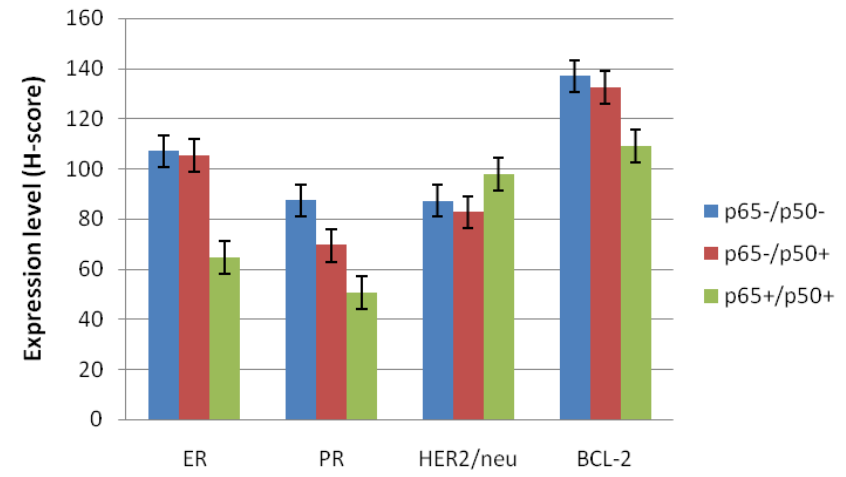

Figure 5: Correlation between NF-KB expression profile and expression of other markers.

No relationship between expression of studied markers and clinical characteristics (age, stage, axillary lymph node status) was found.

Analysis of molecular markers expression showed the relationship between many of them. Thus, it was shown the direct correlation between expression levels of Her $2 /$ neu and cell proliferation $(\mathrm{p}=0,004)$, and the inverse - between Her $2 /$ neu expression and ER ( $p=0,003), P R$ $(\mathrm{p}=0.001)$ and $\mathrm{Bcl}-2(\mathrm{p}<0.001)$ (Figure 2$)$.

In addition, the proliferation rate was also inversely correlated with expression of steroid hormone receptors (ER, PR: $\mathrm{p}<0,01)$ and $\mathrm{Bcl}-2$ $(\mathrm{p}<0,01)$, and directly - with the accumulation of $\mathrm{p} 53(\mathrm{p}<0,01)$ (Figure $3)$.

It was found the direct correlation between expression level of Bcl-2 and: steroid hormone receptors (ER, PR: $\mathrm{p}<0,01$ ), E-cadherin ( $\mathrm{p}$ $<0,01$ ); and also reverse - between Bcl-2 and p65 (Figure 4).

To study the relationship of markers expression and expression profile of NF- $\kappa B$, we divided patients into 3 groups: I - with high levels of p50 and p65 nuclear expression; II - with high p50 and low p65 levels; III - with low levels of p50 and p65. The inverse correlation of NF- $\kappa B$ expression with receptors of steroid hormones $(E R \mathrm{p}=0,016 ; P R$ : $\mathrm{p}=0,056)$ and $\mathrm{Bcl}-2(\mathrm{p}=0,009)$; and direct correlation between NF- $\kappa \mathrm{B}$ and Her $2 /$ neu expression ( $\mathrm{p}=0,011$ ) were found (Figure 5).

\section{Discussion}

These data suggest a division of invasive ductal carcinoma of breast by immunophenotype into several groups. Based on this molecular heterogeneity the classification of breast cancer was compiled [24]. 
The largest group is formed by tumours with positive status of steroid hormone receptors, which corresponds luminal A and B subtypes. In our study, these tumours usually had low Grade; negative Her2/neu and p53 status, low level of nuclear expression of NF- $\mathrm{KB}$ subunits and proliferation, high levels of Bcl-2 and E-cadherin expression. Such molecular profile indicates the preservation by tumour cell adhesive properties, the ability to apoptosis and sensitivity to hormone therapy, and is associated with less aggressive tumour properties and agreed with literature data about good prognosis of disease flowing in patients with this immunophenotype [7-12,25-28].

Another large group consists of receptor-negative tumours (ER-PR-). Among these, one part is Her2/neu amplified (Her2/neu subtype) and another - Her2/neu negative (basal subtype), but they often have common characteristics. Thus, these tumours are usually poorly differentiated, have a sense mutations in the p53 gene, a high proliferation rate, low expression of $\mathrm{Bcl}-2$ and E-cadherin. In addition, it was found that these tumours are often characterized by high nuclear expression of both subunits of NF- $\kappa \mathrm{B}$, which leads to its activation and influence on transcription of target genes. All these characteristics can explain the data of other authors about high malignancy of receptornegative tumours, their resistance to chemotherapy and poor prognosis of disease flowing [7-12,25-28].

The last group is formed of tumours with positive status of steroid hormone receptors and Her2/neu and by the molecular classification belong to hybrid subtype. In our study these tumours had different Grade, characterized by a wide variation in expression level of all investigated markers. As a result, these tumours can be viewed as moderately aggressive, which agrees with the literature data about intermediate prognosis of the disease flowing in these patients [712,25-28].

So, despite the fact that the basis for the choice of treatment strategy is the status of steroid hormone receptors and Her2/neu, it is appropriate to expand the range of the studied markers because they give additional information about tumour and promote the individualization therapeutic schemes. Thus, according to our results the highest level of NF- $\mathrm{kB}$ detected in the receptor-negative (ERPR-), and Her2/neu positive tumours that are associated with poor prognosis. These data may indicate poor prognosis and resistance to chemotherapy in breast cancer patients with activated NF- $\kappa B$, but this, in our opinion, requires further research and retrospective analysis of large number of patients.

\section{Summury}

1. Shown that Grade was in direct correlation with Ki-67 and p65 expression level, and in inverse - with ER, PR and Bcl-2.

2. The level of proliferation tumor also was in inverse relation with expression level of ER, PR and Bcl-2, and in direct - with the status of p53 and Her2/neu.

3. The direct correlation of the level of Bcl-2 expression with ER, $\mathrm{PR}$ and E-cadherin, and the inverse - with p65 subunit of NF$\kappa \mathrm{B}$ was found.

4. Established that the highest nuclear expression of NF- $\kappa B$ subunits (p50 and R65) occurs in tumors with low expression of Bcl-2 negative status ERi PR, and positive -Her2/neu.

\section{References}

1. Fedorenko ZP, Gaysenko AV, Gulak LO (2010) Cancer in Ukraine, 2008-2009: bulletin of national cancer registry of Ukraine, 11: 5
2. Hanahan D, Weinberg RA (2000) The hallmarks of cancer. Cell 100: 57-70.

3. Gazzeri S, Brambilla E, Caron de Fromentel C, Gouyer V, Moro D, et al. (1994) p53 genetic abnormalities and myc activation in human lung carcinoma. Int $\mathrm{J}$ Cancer 58: 24-32.

4. Kluck RM, Bossy-Wetzel E, Green DR, Newmeyer DD (1997) The release of cytochrome $\mathrm{c}$ from mitochondria: a primary site for $\mathrm{Bcl}-2$ regulation of apoptosis. Science 275: 1132-1136

5. Hockenbery D, Nuñez G, Milliman C, Schreiber RD, Korsmeyer SJ (1990) Bcl-2 is an inner mitochondrial membrane protein that blocks programmed cell death. Nature 348: 334-336

6. Lee KH, Im SA, Oh DY, Lee SH, Chie EK, et al. (2007) Prognostic significance of bcl-2 expression in stage III breast cancer patients who had received doxorubicin and cyclophosphamide followed by paclitaxel as adjuvant chemotherapy. BMC Cancer 7: 63.

7. Bozzetti C, Nizzoli R, Naldi N, Guazzi A, Camisa R, et al. (1999) Bcl-2 expression on fine-needle aspirates from primary breast carcinoma: correlation with other biologic factors. Cancer 87: 224-230.

8. Dema A, Dragan S, Lazar E (2008) Bcl-2 expression in breast carcinomas in postmenopausal women. TMJ, 58: 155-61.

9. Berardo MD, Elledge RM, de Moor C, Clark GM, Osborne CK, et al. (1998) bcl-2 and apoptosis in lymph node positive breast carcinoma. Cancer 82: 12961302.

10. Ino Y, Gotoh M, Sakamoto M, Tsukagoshi K, Hirohashi S (2002) Dysadherin a cancer-associated cell membrane glycoprotein, down-regulates E-cadherin and promotes metastasis. Proc Natl Acad Sci U S A 99: 365-370.

11. Wadlow RC, Wittner BS, Finley SA, Bergquist H, Upadhyay R, et al. (2009) Systems-level modeling of cancer-fibroblast interaction. PLoS One 4: e6888.

12. EIMoneim HM, Zaghloul NM (2011) Expression of E-cadherin, N-cadherin and snail and their correlation with clinicopathological variants: an immunohistochemical study of 132 invasive ductal breast carcinomas in Egypt. Clinics (Sao Paulo) 66: 1765-1771.

13. Meteoglu I, Erdogdu IH, Meydan N, Erkus M, Barutca S (2008) NF-KappaB expression correlates with apoptosis and angiogenesis in clear cell renal cell carcinoma tissues. J Exp Clin Cancer Res 27: 53.

14. Wang CY, Mayo MW, Baldwin AS Jr (1996) TNF- and cancer therapy-induced apoptosis: potentiation by inhibition of NF-kappaB. Science 274: 784-787.

15. Montagut C, Tusquets I, Ferrer B, Corominas JM, Bellosillo B, et al. (2006) Activation of nuclear factor-kappa $B$ is linked to resistance to neoadjuvan chemotherapy in breast cancer patients. Endocr Relat Cancer 13: 607-616.

16. Mayo MW, Wang CY, Cogswell PC, Rogers-Graham KS, Lowe SW, et al. (1997) Requirement of NF-kappaB activation to suppress p53-independent apoptosis induced by oncogenic Ras. Science 278: 1812-1815.

17. Bassères DS, Ebbs A, Levantini E, Baldwin AS (2010) Requirement of the NFkappaB subunit p65/RelA for K-Ras-induced lung tumorigenesis. Cancer Res 70: 3537-3546.

18. Beg AA, Baltimore D (1996) An essential role for NF-kappaB in preventing TNFalpha-induced cell death. Science 274: 782-784

19. Van Antwerp DJ, Martin SJ, Kafri T, Green DR, Verma IM (1996) Suppression of TNF-alpha-induced apoptosis by NF-kappaB. Science 274: 787-789.

20. Zhou BP, Hu MC, Miller SA, Yu Z, Xia W, et al. (2000) HER-2/neu blocks tumor necrosis factor-induced apoptosis via the Akt/NF-kappaB pathway. J Biol Chem 275: 8027-8031.

21. Biswas DK, Shi Q, Baily S, Strickland I, Ghosh S, et al. (2004) NF-kappa B activation in human breast cancer specimens and its role in cell proliferation and apoptosis. Proc Natl Acad Sci U S A 101: 10137-10142.

22. Gershtein ES, Scherbakov AM, Platova AM, Tchemeris GY, Letyagin VP, et al. (2010) The expression and DNA-binding activity of NF-1 $\left.\right|^{\circ} B$ nuclear transcription factor in the tumors of patients with breast cancer. Bull Exp Biol Med 150: 71 74.

23. Baldwin AS (2001) Control of oncogenesis and cancer therapy resistance by the transcription factor NF-kappaB. J Clin Invest 107: 241-246.

24. Dabbs DJ. (2010) Diagnostic immunohistochemistry: theranostic and genomic applications, 3rd edn Philadelphia: Saunders (Elsevier Science). 
Citation: Shapochka DO, Zaletok SP, Gnidyuk MI (2013) Expression of Molecular Markers in Tumours of Patients with Breast Cancer. J Cytol Histol 4: 184. doi: 10.4172/2157-7099.1000184

Page 6 of 6

25. Friedl P, Wolf K (2010) Plasticity of cell migration: a multiscale tuning model. J Cell Biol 188: 11-19.

26. Polishchuk L.Z, Riabtseva O.D, Lukianova N.Y, Chekhun V.F. (2011) The adhesion molecules and their importance in cancer development. Oncology, 13: $4-11$.
27. Hugo H, Ackland ML, Blick T, Lawrence MG, Clements JA, et al. (2007) Epithelial--mesenchymal and mesenchymal--epithelial transitions in carcinoma progression. J Cell Physiol 213: 374-383.

28. Gos M, MiÅ,oszewska J, Przybyszewska M (2009) [Epithelial-mesenchymal transition in cancer progression]. Postepy Biochem 55: 121-128. 